DOCTRINA

\title{
Una defensa de la sentencia Gonzáles Lluy con Ecuador dictada por la Corte Interamericana de Derechos Humanos
}

\author{
A defense of the judgment Gonzáles Lluy v. Ecuador \\ delivered by the Inter-American Court of Human Rights
}

\section{Celeste Novelli (iD y Federico de Fazio \\ Universidad de Buenos Aires, Argentina}

\begin{abstract}
RESUMEN Este artículo tiene el propósito de defender grosso modo el razonamiento seguido por la Corte Interamericana de Derechos Humanos en la sentencia Gonzáles Lluy con Ecuador. Nuestra exposición estará estructurada del siguiente modo: en primer lugar, se describirán los hechos del caso. En segundo y tercer lugar, se analizará y evaluará la manera en que la Corte utilizó, por un lado, el argumento relativo a estereotipos y, por el otro, el examen de proporcionalidad. Luego, se considerará y refutará aquella objeción dirigida en contra del uso del examen de proporcionalidad que se apoya en la noción de contenido mínimo de los derechos sociales. Por último, presentaremos nuestras conclusiones a modo de resumen.
\end{abstract}

PALABRAS CLAVE Derecho a la educación, análisis de estereotipos, examen de proporcionalidad, Corte Interamericana de Derechos Humanos, Gonzáles Lluy con Ecuador.

ABSTRACT The main goal of this article is to roughly defend the reasoning followed by the Inter-American Court of Human Rights in the case of Gonzáles Lluy v. Ecuador. The paper will be structured according to the following order: first, we will describe the facts of the case. In second and third place, we will analyse and asses the way in which the Court used, on the one hand, the argument regarding stereotypes and, on the other, the proportionality test. Next, we will consider and refute the objection regarding the use of the proportionality test based on the notion of minimum content of social rights. Finally, we will present our conclusions as a summary.

KEYWORDS Right to education, stereotype analysis, proportionality test, Inter-American Court of Human Rights, Gonzáles Lluy v. Ecuador. 


\section{Introducción}

Este artículo trata sobre la sentencia Gonzáles Lluy con Ecuador, dictada por la Corte

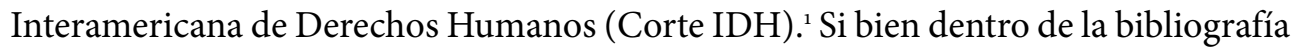
que se ha dedicado al estudio de este fallo existe un extendido consenso respecto de la resolución o conclusión arribada por parte de la Corte IDH, aún persiste un importante debate en torno a la manera en que argumentó. Así, por ejemplo, hay quienes critican que la Corte IDH no haya utilizado el estándar del contenido mínimo de los derechos sociales y enfatizan que, debido a ello, su fallo «se quedó a mitad de camino». ${ }^{2}$

En claro contraste con esta objeción, el propósito de este artículo es defender grosso modo el razonamiento seguido por la Corte IDH en el caso bajo análisis. Sin perjuicio de algunos matices que serán oportunamente señalados, nuestra hipótesis es que los fundamentos del fallo son básicamente correctos. A los fines de corroborar esta hipótesis, desplegaremos una argumentación respetando el siguiente orden de exposición: en primer lugar, se describirán los hechos del caso; en segundo y tercer lugar, se analizará y evaluará la manera en que la Corte IDH utilizó, por un lado, el argumento relativo a estereotipos y, por el otro, el examen de proporcionalidad; en cuarto lugar, se refutará aquella objeción dirigida en contra del uso del examen de proporcionalidad que se apoya en la noción de contenido mínimo de los derechos sociales; por último, presentaremos nuestras conclusiones a modo de resumen.

\section{Los hechos del caso}

Talía Gonzáles Lluy nació el 8 de enero de 1995 en Cuenca, Ecuador. ${ }^{3}$ Cuando solo tenía tres años de edad, fue diagnosticada con la enfermedad hemorrágica púrpura trombocitopénica idiopática ${ }^{4}$ se le ordenó una urgente transfusión de sangre y plaquetas, ${ }^{5}$ la que llevó a cabo el banco de sangre de la Cruz Roja el 22 de junio de

1. Caso Gonzáles Lluy y otros con Ecuador, Corte Interamericana de Derechos Humanos, 1 de septiembre de 2015, disponible en https://bit.ly/3r6cDLW.

2. En este sentido, Ronconi (2016: 127) sostiene: «El análisis de los argumentos utilizados por la Corte IDH me permite cuestionar aquellos argumentos que no aparecieron, pero que habrían resultado necesarios para el otorgamiento de plena justiciabilidad a los DESC [derechos económicos, sociales y culturales] en el sistema interamericano».

3. Caso Gonzáles Lluy y otros con Ecuador, foja 64.

4. «La púrpura trombocitopénica idiopática es una enfermedad hemorrágica caracterizada por la destrucción prematura de plaquetas debido a la unión de un autoanticuerpo, habitualmente de la clase IgG, a las glucoproteínas plaquetarias y la posterior depuración por el sistema fagocítico mononuclear». Guía de Práctica Clínica, Diagnóstico y Tratamiento de Púrpura Trombocitopénica Inmunológica, México, Secretaría de Salud, 2009, disponible en https://bit.ly/3yUUio1.

5. Caso Gonzáles Lluy y otros con Ecuador, foja 75. 
1998. Un mes después, Talía recibió la noticia de que, debido a un proceder negligente durante la transfusión, había sido infectada con el virus del VIH. ${ }^{6}$ Esta situación motivó a su madre, Teresa Lluy, a plantear varias demandas en instancias penales y civiles que, ya sea por prescripción o nulidad, no condujeron a un resultado a favor de su hija. ${ }^{7}$

En septiembre de 1999, cuando Talía tenía cinco años, fue inscrita en la escuela pública de educación básica Zolia Aurora Palacios de la ciudad de Cuenca. Durante los primeros dos meses, Talía asistió a clases con normalidad. Sin embargo, entrado el mes de noviembre, las autoridades de la escuela tomaron conocimiento de su enfermedad y decidieron suspenderla «hasta ver qué decían las autoridades de [la subsecretaría local de] educación». ${ }^{8}$ En el transcurso de ese tiempo, funcionarios de la Subdirección de Salud impartieron charlas sobre el VIH y destacaron las bajas probabilidades de su contagio. Con todo, el 3 de febrero del 2000, el director de la escuela decidió finalmente expulsar a Talía. ${ }^{9}$

Como consecuencia, Teresa Lluy presentó una acción de amparo ante el Tercer Tribunal Distrital en lo Contencioso Administrativo (con sede en Cuenca) en contra del Ministerio de Educación y Cultura y las autoridades de la escuela, en la que solicitaba que se declarara la violación del derecho a la educación de Talía y se ordenara su reincorporación a la escuela, además de una reparación económica por los daños provocados. El 9 de febrero se celebró la audiencia pública del caso, en la que las partes demandadas ofrecieron sus defensas. En primer lugar, el subsecretario regional del Ministerio de Educación y Cultura argumentó que

el director de la escuela y la profesora habían procedido [para asegurar] que Talía no contagiara su lamentable enfermedad al resto de los niños [...], puesto que, si bien a ella le asistían garantías constitucionales, [...] también debían gozar de estas garantías y derechos [...] la gran mayoría de la niñez que se educaba en ese centro. ${ }^{10}$

En segundo lugar, el director de la escuela alegó que su decisión procuraba cuidar la salud del resto de los niños, ya que

en la escuela Talía tuvo algunas hemorragias debido a [la] enfermedad púrpura trombocitopénica, [lo que] hacía que los riesgos de contagios fueran mayores. También porque Talía se encontraba en el primer año de educación básica en donde se trabajaba con objetos cortopunzantes. ${ }^{11}$

\footnotetext{
6. Caso Gonzáles Lluy y otros con Ecuador, foja 82.

7. Caso Gonzáles Lluy y otros con Ecuador, foja 85.

8. Caso Gonzáles Lluy y otros con Ecuador, foja 133.

9. Caso Gonzáles Lluy y otros con Ecuador, foja 134.

10. Caso Gonzáles Lluy y otros con Ecuador, foja 137.

11. Caso Gonzáles Lluy y otros con Ecuador, foja 138.
} 
En tercer lugar, la profesora indicó que

ella había preguntado al médico tratante de Talía [...] si existía un riesgo para el resto de [sus] compañeros [...] y que el médico le había contestado que sí había riesgo, pero en un pequeño porcentaje.

Señaló, además, que

tenía testigos de aquellas hemorragias que tenía [Talía y que] se había seguido el camino correcto, pero no para hacerle daño moral y sicológico a Talía, sino [para preservar a] un grupo de 31 niños. ${ }^{12}$

El 11 de febrero del 200o, el Tribunal Contencioso procedió a dictar su veredicto. Si bien reconoció que en el caso concurría un conflicto entre, por un lado, el derecho a la educación de Talía y, por el otro, el interés de evitar el riesgo de contagio por parte de un conglomerado estudiantil y del resto del personal de la escuela, optó por darle prioridad a este último sobre la base de un razonamiento de tipo utilitarista, esto es, atendiendo el beneficio del mayor número de personas involucradas. Esto lo hizo explícito con la siguiente frase:

Frente a ese conflicto era obvio señalar que prevalece el derecho de la mayoría con respecto a un caso particular. ${ }^{13}$

Como conclusión, el tribunal resolvió rechazar la acción de amparo y manifestar que lo más adecuado era que Talía ejerciera su derecho a la educación «mediante una instrucción particularizada y a distancia». ${ }^{14}$ Posteriormente, en 2014, el caso llegó ante los estrados de la Corte IDH. El problema jurídico que la Corte IDH debió abordar era si la decisión de expulsar a Talía de la escuela primaria Zolia Aurora Palacios, con la finalidad de proteger la salud e integridad física de sus compañeros y del personal de la escuela, era violatorio o no del derecho a la educación de la niña ${ }^{15}$ (de acuerdo con lo prescripto por los artículos 26 y 1.1 de la Convención Americana sobre Derechos Humanos ${ }^{16}$ y el artículo 13 del Protocolo de

\footnotetext{
12. Caso Gonzáles Lluy y otros con Ecuador, foja 139.

13. Caso Gonzáles Lluy y otros con Ecuador, foja 143.

14. Caso Gonzáles Lluy y otros con Ecuador, foja 144.

15. Caso Gonzáles Lluy y otros con Ecuador, foja 233.

16. Artículo 26 de la Convención Americana sobre Derechos Humanos: «Los Estados parte se comprometen a adoptar providencias, tanto a nivel interno como mediante la cooperación internacional, especialmente económica y técnica, para lograr progresivamente la plena efectividad de los derechos que se derivan de las normas económicas, sociales y sobre educación, ciencia y cultura, contenidas en la Carta de la Organización de los Estados Americanos, reformada por el Protocolo de Buenos Aires, en la medida de los recursos disponibles, por vía legislativa u otros medios apropiados». Artículo 1.1: «Los Estados parte en esta Convención se comprometen a respetar los derechos y libertades reconocidos en
} 
San Salvador). ${ }^{17}$ A diferencia de lo decidido por el tribunal con sede en Cuenca, la Corte IDH consideró que el Estado ecuatoriano sí era responsable de haber vulnerado el derecho a la educación de Talía. Respaldó su decisión sobre la base de dos argumentos principales que, en resumidas cuentas, señalan que la medida adoptada por parte de las autoridades educativas no solo supone un uso discriminatorio de estereotipos referidos a personas que portan con VIH, sino que, además, resulta desproporcionada en un sentido amplio. Por razones analíticas, es conveniente analizar estos dos argumentos por separado.

\section{El uso del argumento relativo a estereotipos}

El primer argumento que utiliza la Corte IDH para evaluar si hubo o no violación al derecho a la educación fue el análisis de ideas estereotipadas respecto de personas que portan el virus del VIH. A partir de la transcripción de los dichos de Talía en la audiencia pública, así como de la referencia a informes de organismos internacionales - como ONUSIDA-, la Corte describe a grandes rasgos las experiencias de discriminación que viven cotidianamente las personas que tienen esta enfermedad. $\mathrm{Al}$ ser este el factor en común, las experiencias se repiten y permiten caracterizar vivencias representativas de las personas que conforman este grupo. Para entender el argumento sobre los estereotipos, es preciso tener en cuenta que, por el solo hecho de que una persona es asociada mentalmente a un grupo, se genera la convicción - por lo general inconsciente- de que el individuo posee ciertas características particulares, o que asumirá una serie de conductas, o que debe actuar de una determinada manera. Asimismo, es usual que los estereotipos estén asociados a características que están fuera del control de las personas, como los atributos físicos o las enfermedades, y que establezcan jerarquías al atribuir valores positivos o negativos a la posesión de dichos rasgos. ${ }^{18}$

Con anterioridad a esta sentencia, la Corte IDH había comenzado a incursionar en el análisis de estereotipos a partir del caso Campo Algodonero con México. Allí brindó una definición sobre la estereotipia ejercida por parte de los agentes estatales que ignoraron las denuncias sobre mujeres desaparecidas en Ciudad Juárez y omitieron la activación de los mecanismos de búsqueda. En este sentido, la Corte IDH mencionó algunos de los efectos que tiene la reproducción de estereotipos:

ella y a garantizar su libre y pleno ejercicio a toda persona que esté sujeta a su jurisdicción, sin discriminación alguna por motivos de raza, color, sexo, idioma, religión, opiniones políticas o de cualquier otra índole, origen nacional o social, posición económica, nacimiento o cualquier otra condición social».

17. Artículo 13 del Protocolo de San Salvador: «1. Toda persona tiene derecho a la educación. [...] 3. Los Estados parte en el presente Protocolo reconocen que, con objeto de lograr el pleno ejercicio del derecho a la educación: a) la enseñanza primaria debe ser obligatoria y asequible a todos gratuitamente».

18. Véase, por ejemplo, Clérico (2017), Timmer (2011) y Cardoso Onofre de Alencar (2016). 
El estereotipo de género se refiere a una preconcepción de atributos o características poseídas o papeles que son o deberían ser ejecutados por hombres y mujeres respectivamente. Teniendo en cuenta las manifestaciones efectuadas por el Estado [...], es posible asociar la subordinación de la mujer a prácticas basadas en estereotipos de género socialmente dominantes y socialmente persistentes, condiciones que se agravan cuando los estereotipos se reflejan, implícita o explícitamente, en políticas y prácticas, particularmente en el razonamiento y el lenguaje de las autoridades de policía judicial, como ocurrió en el presente caso. La creación y uso de estereotipos se convierte en una de las causas y consecuencias de la violencia de género en contra de la mujer. ${ }^{19}$

Los estereotipos tienen que ver con lo que las personas representan ante la mirada del otro, no con lo que las personas realmente son, ya que ante todo constituyen creencias que nos permiten clasificar el mundo que nos rodea. Tienen, sin duda, una función cognitiva, debido a que nos permiten organizar el mundo, es decir, asignar características a personas y objetos que creemos que comparten ciertos rasgos en común. Muchas veces este rasgo es en verdad compartido, otras tantas no. En este último supuesto, cuando el estereotipo atribuye una percepción generalizada a un individuo de manera errónea, puede producir sobre él juicios y decisiones injustas, dado que coloca una etiqueta a la otra persona que, en muchas ocasiones, no corresponde con su realidad (Cardoso Onofre de Alencar, 2016: 31).

Con frecuencia, cuando se toma conocimiento de que alguien padece una enfermedad como el VIH, el efecto inmediato es su estigmatización, es decir, su exclusión de diversos ámbitos sociales como el trabajo, la educación y los vínculos afectivos. A esto se le suma la propia autoexclusión por parte de quienes portan la afección. Al respecto son ilustrativas las palabras de Talía en la audiencia pública llevada adelante en el trámite del caso ante el tribunal interamericano:

Tenía mucho miedo llevarme con la gente [sic], pensaba que se iban a enterar que tenía VIH y me horrorizaba pensar que me maltraten o me aíslen, por lo que prefería pasar sola $[\ldots]$ así pasé con escasas amigas con quienes era difícil conversar de los temas normales: moda, bailes, música, novios. ${ }^{20}$

La estigmatización provoca que, sobre la base de experiencias de rechazo previas, las personas afectadas eviten situaciones sociales cotidianas por el temor a la marginación:

19. Sentencia del caso González y otras ("Campo Algodonero») con México, Corte Interamericana de Derechos Humanos, serie C núm. 205, excepciones preliminares, fondo, reparaciones y costas. 25 de noviembre de 2009 , foja 401.

20. Expediente del Caso Gonzáles Lluy, escrito de alegatos finales de los representantes de las presuntas víctimas, foja 75, 20 de mayo de 2015, disponible en https://bit.ly/3yUjIlP. 
Yo tenía muchas amigas, pero después de mi enfermedad sus papás no les dejaban jugar conmigo. Me veían feo, ya no me querían saludar ni mirar. Se alejaban, como si me tuvieran miedo. Me sentía muy sola, no entendía por qué [...] Quiero estar con mi enamorado, abrazarlo, disfrutar de momentos como pareja, bailar, pasear y no tener miedo de que se entere y me margine, termine conmigo o me odie por tener VIH. Tengo terror al rechazo.

En este caso, la Corte fundamentó cómo el estereotipo asociado a la enfermedad afectó negativamente a Talía, limitando en forma discriminatoria su acceso a la educación. Veamos el paso a paso del argumento.

En primer lugar, la Corte identificó que la diferencia de trato que supuso la exclusión de Talía de la escuela estuvo basada en una condición médica: ser portadora del virus del VIH y padecer la enfermedad de la púrpura trombocitopénica idiopática. Esta condición médica constituye una de las categorías prohibidas de discriminación que se subsume en la expresión "otra condición social» del artículo 1.1 de la Convención Americana. ${ }^{21}$ La consecuencia de incluirla dentro del artículo 1.1 es que el escrutinio judicial de la medida que está basada en dicha categoría sospechosa deba ser más estricto, porque a priori está prohibida. De este modo, el uso de la categoría solo podría ser aceptado si, invirtiendo la carga de la prueba, el Estado demuestra «necesidades imperiosas», ${ }^{22}$ razones "particularmente serias» y «una argumentación exhaustiva». ${ }^{23}$ En estas circunstancias concretas, el Estado debía demostrar entonces que la exclusión de Talía de la entidad educativa no tenía una finalidad o un efecto discriminatorio. Esto nos lleva al siguiente paso.

En segundo lugar, la Corte analizó las razones ofrecidas por el Estado. La separación de Talía pretendió justificarse bajo el argumento de que su permanencia en el aula podía provocar el contagio del resto de los niños y personal de la escuela, debido a sus episodios hemorrágicos y el uso de objetos punzantes. Este argumento fue luego avalado en la sentencia dictada por el Tercer Tribunal en lo Contencioso de la ciudad de Cuenca. No obstante, de dicho fallo surge que en sus certificados médicos

los doctores J. O. M. y N. V. [...] indicaron que Talía era una paciente del virus de inmunodeficiencia humana hasta ese momento asintomática, y que además se encontraba en buenas condiciones hematológicas. Asimismo, se encuentran las declaraciones de R. G., trabajador social de la Dirección de Salud quien coordinó la capacitación al cuerpo docente y administrativo de la escuela Zoila Aurora Palacios sobre el VIH/sida, quien explicó que el virus era una realidad con la que se debía aprender a convivir, y que existían riesgos que podrían ser mínimos si se tenían en cuenta las normas de bioseguridad. ${ }^{24}$

\footnotetext{
21. Caso Gonzáles Lluy y otros con Ecuador, foja 255.

22. Caso Gonzáles Lluy y otros con Ecuador, foja 256.

23. Caso Gonzáles Lluy y otros con Ecuador, foja 257. Véase también foja 260.

24. Caso Gonzáles Lluy y otros con Ecuador, foja 250. El destacado es nuestro.
} 
Teniendo en consideración los documentos mencionados, la Corte consideró que las razones interpuestas para separar a Talía de la escuela se encontraban refutadas en virtud de los informes médicos que, evaluando específicamente la situación, aseveraban un bajo riesgo de contagio de cumplirse con unas mínimas normas de prevención. En este sentido, era evidente que las autoridades educativas y judiciales habían basado sus decisiones en creencias genéricas e infundadas acerca de las personas infectadas con el virus del HIV. Por lo tanto, la Corte IDH concluyó que el interés colectivo alegado por parte del Estado resulta insuficiente para justificar la diferencia de trato, y esto lo hace explícito por medio del siguiente enunciado:

No son admisibles las consideraciones basadas en estereotipos por la situación de salud de las personas, es decir, preconcepciones de los atributos, conductas o características poseídas por las personas que conviven con cierta enfermedad o el riesgo que dicha enfermedad pueda tener para otras personas. ${ }^{25}$

A la luz del examen estricto de igualdad, se pone en evidencia que las razones del Estado no eran lo suficientemente objetivas y serias para justificar una restricción en el acceso al derecho a la educación por parte de Talía. De este modo, el trato diferenciado devino discriminatorio.

Hasta aquí, el análisis permitió determinar si la medida cuestionada estuvo basada en estereotipos y si su efecto fue discriminatorio. A continuación, y como tercer paso, surge un nuevo interrogante: si las autoridades efectivamente tomaron conocimiento de la existencia de estereotipos en torno a personas (en particular niñas y niños) con $\mathrm{VIH}$, entonces ¿qué medidas tomaron para combatirlos? En este punto, el argumento de estereotipos abona también al contenido de las restantes obligaciones del Estado inherentes al derecho a la educación de personas con VIH. Según la enumeración de la Corte IDH, estas obligaciones son: i) disponer de información oportuna y libre de prejuicios sobre el VIH/sida; ii) que no se les impida el acceso a los centros educativos; y iii) que la educación promueva su inclusión y no discriminación dentro del entorno social. ${ }^{26}$

El estigma alrededor de la enfermedad hace que una persona portadora del virus -o que se presupone que lo porta- experimente barreras sociales y actitudinales que, como resultado de lo anterior, obstaculizan el acceso en condiciones de igualdad al ejercicio de los derechos. ${ }^{27}$ Dada esta condición de vulnerabilidad $-\mathrm{y}$, además, que se trata de una niña-, el Estado tiene el deber de promover su inclusión, en especial en el ámbito educativo. En lo concreto, la obligación se materializa en un deber de

25. Caso Gonzáles Lluy y otros con Ecuador, foja 269.

26. Caso Gonzáles Lluy y otros con Ecuador, foja 241.

27. Caso Gonzáles Lluy y otros con Ecuador, foja 236. 
proveer una atención especializada que tenga en cuenta las necesidades específicas, ${ }^{28}$ lo que exige la adaptabilidad de la escuela pública. Por otro lado, su inclusión requiere que el Estado adopte medidas para combatir los prejuicios en torno a la enfermedad, es decir, garantizar el derecho a disponer de información adecuada a través de la educación, capacitación e implementación de diversos programas que erradiquen prejuicios e ideas estereotipadas sobre las personas portadoras del virus VIH. ${ }^{29}$ Por el contrario, las autoridades no solo no le brindaron a Talía una atención personalizada que garantizara su propia seguridad y la del resto del alumnado, sino que además optaron por excluirla, a pesar de que recaía sobre ellas un deber de diligencia reforzado en virtud de tratarse del derecho de educación de una niña y con VIH.

En suma, el argumento de estereotipos se compone de una serie de pasos. En el primero, se identifica el estereotipo en juego que sustenta la medida cuestionada. Luego se analiza si las razones estatales alegadas para justificar el uso del estereotipo son válidas bajo el estándar de un examen estricto de igualdad. Finalmente, una vez identificado el estereotipo y su efecto perjudicial o discriminatorio, se evalúa el cumplimiento de las obligaciones específicas del Estado respecto de la erradicación del estereotipo en juego en el caso concreto.

\section{El uso del examen de proporcionalidad}

Hasta aquí, la Corte IDH se ha limitado a decir que el uso de estereotipos referidos a personas que portan con $\mathrm{VIH}$, por parte de las autoridades escolares, ministeriales y judiciales, supone una limitación discriminatoria del derecho a la educación de Talía y que, por tanto,

es responsabilidad del Estado determinar que efectivamente exista una causa razonable $[\ldots]$ para haber hecho la distinción. ${ }^{30}$

A los fines de determinar la razonabilidad de la argumentación alegada por el Estado, la Corte IDH procedió a hacer uso del examen de proporcionalidad. ${ }^{31}$ Por medio de este razonamiento llegó a la conclusión de que la expulsión de Talía representaba una medida desproporcionada en sentido amplio como consecuencia de su ausencia de idoneidad y necesidad. En término generales, es difícil no estar de acuerdo con esta conclusión arribada por la Corte IDH. Sin embargo, sí es posible plantear algunos reparos respecto del modo en que la Corte IDH usa uno de los pasos del examen de proporcionalidad; en particular, el subexamen de idoneidad.

\footnotetext{
28. Caso Gonzáles Lluy y otros con Ecuador, foja 262.

29. Caso Gonzáles Lluy y otros con Ecuador, foja 263.

30. Caso Gonzáles Lluy y otros con Ecuador, foja 257.

31. Caso Gonzáles Lluy y otros con Ecuador, foja 257.
} 
De acuerdo con el subexamen de idoneidad, cualquier conducta que limite a un derecho debe contribuir, por lo menos, con el fomento de algún fin legítimo (Clérico, 2009: 40). De esta definición se deriva que la conducta bajo análisis carga con dos exigencias diferenciables: en primer lugar, debe perseguir un fin legítimo o permitido $y$, en segundo lugar, debe ser técnicamente adecuada para promoverlo. Con respecto a la primera exigencia, la Corte IDH consideró, con razón, que la decisión de expulsar a Talía perseguía un fin permitido. Esto lo hizo explícito en la siguiente frase:

La Corte resalta que el objetivo general de proteger la vida e integridad personal de las niñas y niños [y demás personal] que compartían su estancia con Talía en la escuela constituye, en sí mismo, un fin legítimo y es, además, imperioso. ${ }^{32}$

Sin perjuicio de ello, consideró a renglón seguido que la mencionada medida no lograba cumplir con la segunda exigencia, esto es, el mandato de promover técnicamente al fin legítimo previamente determinado. En este sentido, sostuvo que

[el uso] de presunciones infundadas y estereotipadas sobre los riesgos que puede generar el VIH no es adecuad[o] para garantizar el fin legítimo. ${ }^{33}$

Ahora bien, cabe dudar que en este último paso la corte IDH haya efectuado un uso admisible del subexamen de idoneidad. Ciertamente, la Corte IDH tiene razón cuando afirma que las sucesivas decisiones tomadas por parte de las autoridades (escolares, administrativas y judiciales) estuvieron basadas en estereotipos injustificados. Sin embargo, una de las interrogantes que queremos plantear aquí es si esto es suficiente para considerar probada, sin más, la falta de adecuación técnica de la medida adoptada. En definitiva, lo que el subexamen de idoneidad requiere no es que los demandados carezcan de prejuicios (algo que sí demanda el análisis de estereotipos), sino que la conducta adoptada exhiba algún tipo de relación empírico-instrumental con el fin que se pretende o alega perseguir. ${ }^{34} \mathrm{Al}$ ser así, una comprobación semejante

32. Caso Gonzáles Lluy y otros con Ecuador, foja 257.

33. Caso Gonzáles Lluy y otros con Ecuador, foja 266.

34. Esta exigencia surge como consecuencia de la interpretación «débil» del subexamen de idoneidad sugerida por Laura Clérico. De acuerdo con Clérico, cuando se dice que una medida carece de idoneidad, no se quiere decir que no es la opción más eficiente para fomentar el fin, sino (más modestamente) que no contribuye en ningún grado ni aspecto con su fomento (Clérico, 2009: 59). Sin embargo, en un comentario sobre el presente caso, Liliana Ronconi ha puesto en cuestión a esta interpretación «débil». Así, sostiene que la Corte IDH ha hecho un uso adecuado del subexamen de proporcionalidad porque "cuando se aplica la fórmula de la proporcionalidad en forma intensiva [es decir, a partir de una categoría sospechosa] no alcanza con que la medida fomente al fin de alguna manera, [sino que] tiene que existir una relación de fomento bien cercana» (Ronconi, 2016: 125). Sin embargo, esta interpretación «fuerte» propuesta por Ronconi no puede ser aceptada en virtud de dos argumentos. El primer argumento es de índole competencial e indica que si, como resultado del subexamen de idoneidad, solo 
no puede estar basada en la interpretación de los estados mentales o discursos de las autoridades implicadas, sino en la valoración de las opiniones o informes médicos. Justamente, las opiniones médicas referidas al caso no arrojaban como resultado una imposibilidad total de contagio, sino que, por el contrario, afirmaban que «sí había riesgo, aunque en un pequeño porcentaje». ${ }^{35}$ Esto incluso lo hace propio la Corte IDH cuando expresa:

La Corte concluye que el riesgo real y significativo de contagio que pusiese en riesgo la salud de las niñas y niños compañeros de Talía era sumamente reducido. ${ }^{36}$

Por lo tanto, cabe concluir que, a diferencia de lo que entendió la Corte IDH, la decisión de expulsar a Talía era técnicamente idónea - aunque en un grado ínfimamente bajo o reducido- para fomentar el fin de proteger la salud e integridad física tanto de sus compañeros como del personal de la escuela. En todo caso, el hecho de que la medida tuviera una eficacia «sumamente reducida» hubiera sido muy relevante en el análisis de su proporcionalidad en sentido estricto, es decir, en un juicio de ponderación; ${ }^{37}$ pues si se asume, como lo hace la Corte IDH, que la afectación del derecho a la educación de Talía era muy intensa, entonces esta no podría ser compensada por un grado ínfimo en la realización del fin legítimo. Llama la atención que la Corte IDH no profundizó en forma explícita su argumentación en torno a este último subexamen.

En cambio, la Corte IDH sí hizo un uso adecuado del subexamen de necesidad. De acuerdo con él, cualquier medida que limite a un derecho debe ser necesaria para fomentar un fin legítimo (Clérico, 2009: 101). Esto significa que exige verificar si no existe alguna medida alternativa - con respecto a aquella que en efecto fue adoptada - que conduzca a un resultado óptimo, es decir, que por un lado permita promover - por lo menos- en un mismo grado al fin legítimo, pero por el otro sea

permanecieran como válidas aquellas medidas que resulten las más eficaces técnicamente, entonces quedaría seriamente comprometida parte de la discrecionalidad reconocida a favor del Poder Legislativo (Clérico, 2009: 40). El segundo es un argumento de racionalidad y sostiene que, si la relación de fomento fuera entendida en sentido fuerte, muchas medidas quedarían excluidas de antemano del escrutinio correspondiente a los subexámenes de necesidad y proporcionalidad en sentido estricto. De esta forma, se estarían dejando afuera otros posibles argumentos relevantes para la decisión (Clérico, 2009: 41). Sin embargo, la consideración de todos los argumentos constituye un presupuesto necesario para la toma de decisiones racionales. Por tanto, las mejores razones siguen hablando en favor de una interpretación «débil» del subexamen de idoneidad.

35. Caso Gonzáles Lluy y otros con Ecuador, foja 139.

36. Caso Gonzáles Lluy y otros con Ecuador, foja 274.

37. Esta forma de argumentación ha sido explicitada por Robert Alexy (1986: 186) a través de su famosa «ley de la ponderación», que reza: «Cuanto más intensa sea la afectación a un principio, tanto mayor debe ser la importancia de la satisfacción del otro». 
menos lesiva respecto del derecho afectado. Aplicada al caso bajo análisis, esta exigencia supone

determinar si no existían otras medidas diferentes a las del retiro del centro educativo y el confinamiento a una instrucción particularizada y a distancia. ${ }^{38}$

Tomando este criterio como norte, la Corte IDH concluye:

En el marco de un juicio de necesidad [...] de la medida, este Tribunal resalta que el medio escogido constituía la alternativa más lesiva y desproporcionada de las disponibles para cumplir con la finalidad de proteger la integridad de los demás niños [y del personal] del colegio. [Ello en particular porque] no existió adaptabilidad del entorno educativo a la situación de Talía, a través de medidas de bioseguridad o similares que deben [estar presentes] en todo establecimiento educativo para la prevención general de la transmisión de enfermedades. ${ }^{39}$

Como puede verse, la razón por la que sostuvimos que es difícil no estar de acuerdo con la resolución de la Corte IDH se debe, sobre todo, al uso que hace del subexamen de necesidad. Es perfectamente posible pensar en medidas informativas, preventivas o de primeros auxilios que, de haber sido adoptadas, hubieran permitido alcanzar una relación óptima o de equilibrio entre los intereses en juego, esto es, evitar la propagación del contagio del virus VIH sin afectar el derecho a la educación de Talía. Por lo tanto, cabe concluir que la sentencia se encuentra justificada desde el punto de vista del examen de proporcionalidad; y ello sin perjuicio de que la Corte IDH haya no solo utilizado de manera inadecuada el subexamen de idoneidad, sino además omitido hacer referencia al subexamen de proporcionalidad en sentido estricto cuando era pertinente hacerlo.

\section{La objeción basada en el estándar de contenido mínimo}

Sin perjuicio de lo anterior, hay una parte de la teoría especializada en los derechos sociales que objeta el modo de argumentar escogido por la Corte IDH. En particular, se le critica no haber considerado ciertos argumentos que pueden ser más eficaces con relación a la plena justiciabilidad de esta clase de derechos (Ronconi, 2016: 127). Por ejemplo, Ronconi entiende que la Corte IDH yerra al hacer uso del examen de proporcionalidad en un caso que pudo haber sido resuelto de una manera más clara y sencilla con ayuda del estándar de contenido mínimo (Ronconi, 2016: 128). Así, comenta que,

en cuando al derecho a la educación, la aplicación del examen de [proporcionali-

38. Caso Gonzáles Lluy y otros con Ecuador, foja 271.

39. Caso Gonzáles Lluy y otros con Ecuador, foja 274. 
dad] para resolver un caso tan claro de negación de un derecho deja ciertas dudas, ya que lo que está en juego es el contenido mínimo [...]. Lo que está en juego, entonces, es aquel contenido básico del derecho que no se puede ponderar frente a otros principios (Ronconi, 2016: 128).

No obstante, esta objeción no es convincente, sobre todo por algunas razones de orden metodológico que ponen en tela de juicio algunos de los supuestos asumidos por parte de la teoría del contenido mínimo.

Un primer problema por destacar es que los autores que defienden esta teoría utilizan el término contenido mínimo de manera ambigua. Algunos, como es el caso de Bilchitz, entienden al estándar de contenido mínimo como una prioridad ponderada, esto es, como una razón de gran importancia que solo puede ser derrotada excepcionalmente por consideraciones de gran peso (Bilchitz, 2008: 211). Así entendido, el estándar de contenido mínimo deviene redundante, ya que de todas maneras requiere un examen de proporcionalidad (Lehmann, 2006: 184). En cambio, otros autores, como parece ser el caso de Ronconi, lo consideran como una prioridad absoluta, esto es, como una razón que nunca puede ser derrotada. Entendido de este modo, el estándar de contenido mínimo sí es funcionalmente distinguible del examen de proporcionalidad, pero ello lo hace a costa de perder solidez como teoría de la interpretación de los derechos sociales.

Así, un segundo problema vinculado al estándar de contenido mínimo refiere a que la teoría aún no ha podido explicitar un criterio normativo último que permita determinar en abstracto cuál es el contenido mínimo que se corresponde con cada uno de los derechos sociales (Lehmann, 2006: 185; Young, 2012: 90 y ss.). En este sentido, no hay acuerdo con respecto a si dicho contenido mínimo debe ser inferido deductivamente a partir del concepto de «subsistencia», «dignidad», «autonomía personal», «consenso fáctico» o de una combinación de alguno o todos de ellos (Young, 2012: 66-98). Por otra parte, parece difícil que alguna vez pueda alcanzarse un consenso semejante, ya que ello requeriría fundamentar, con antelación, un orden lexicográfico o escalonado de los derechos humanos o bienes básicos, cosa que por el momento no está a la vista.

Ahora bien, Ronconi parece sugerir que el contenido mínimo de - en este casoel derecho a la educación puede ser extraído no ya de un criterio normativo último, sino del artículo 26 de la Convención Americana sobre Derechos Humanos (CADH). Pero esta no parece una interpretación que se corresponda con el tenor literal de dicha cláusula. Así, el artículo 26 de la CADH prescribe lo siguiente:

Los Estados parte se comprometen a adoptar providencias, [...] especialmente económica y técnica, para lograr progresivamente la plena efectividad de los derechos que se derivan de las normas económicas, sociales y sobre educación [...] en la medida de los recursos disponibles, por vía legislativa u otros medios apropiados. 
Como puede notarse, el texto de la citada disposición no solo no habla en ningún momento del deber de cumplir con el contenido mínimo de los derechos sociales, sino que expresamente prescribe realizarlos «en la medida de los recursos disponibles». La diferencia entre estas dos nociones no puede ser más radical, ya que dependiendo de cuál sea esa medida de los recursos disponibles, la obligación del Estado puede ubicarse tanto por debajo como por encima del mentando contenido mínimo (suponiendo, claro está, que este pudiera ser determinado)..$^{\circ}$

Con todo, en este punto podría contraargumentarse que, a partir de la interpretación del texto del artículo 13 (3.a) del Protocolo de San Salvador, sí es posible obtener un contenido básico del derecho a la educación que no es derrotable. En efecto, la cláusula 13 (3.a) del Protocolo prescribe: «La enseñanza primaria debe ser obligatoria $\mathrm{y}$ asequible a todos gratuitamente».

Pero, si bien es cierto que a partir de ese artículo se extrae una obligación concluyente no pasible de limitación, ello no se funda en la idea de contenido mínimo sino, más sencillamente, en la propia literalidad del texto del protocolo. De nuevo, el estándar del contenido mínimo deviene redundante como método para interpretar el significado de dicha cláusula. Por otra parte, no es claro que la existencia de la norma del artículo 13 (3.a) resulte suficiente para resolver el caso Gonzáles Lluy, pues, si bien en forma expresa obliga a brindar una educación primaria asequible y gratuita, no necesariamente prohíbe que esta sea efectuada a distancia. Para concluir esto último, es necesario ofrecer argumentos adicionales.

Todo lo anterior pone de manifiesto que la Corte IDH ha hecho bien en hacer uso del examen de proporcionalidad, dado que se trata de una forma de razonamiento mucho más transparente que el estándar de contenido mínimo o, por lo menos, evidencia menos problemas desde el punto de vista metodológico. ${ }^{41}$ Además, se trata de un método más compatible o coherente con el tenor literal del artículo 26 de la Convención Americana, que prescribe realizar los derechos sociales en la medida de los recursos disponibles.

\section{Conclusiones}

Este artículo tuvo el propósito de defender grosso modo la estrategia de argumentación desplegada por la Corte IDH en el caso Gonzáles Lluy con Ecuador. En dicha sentencia, la Corte IDH decidió que la medida de expulsar a Talía de la escuela pública

40. Una objeción similar a la teoría del contenido mínimo en general se encuentra en Bernal Pulido (2004: 137).

41. Una fundamentación general acerca de las ventajas del examen de proporcionalidad frente al estándar de contenido mínimo puede encontrarse en Bernal Pulido (2003). Un estudio semejante, pero aplicado específicamente al caso de los derechos sociales puede hallarse en De Fazio (2019). 
de educación básica Zolia Aurora Palacios vulneraba su derecho a la educación y, por lo tanto, se encontraba prohibida. Respaldó su fallo sobre la base de dos argumentos principales que, en resumidas cuentas, señalan que la medida adoptada por parte de las representantes del Estado ecuatoriano no solo suponía un uso discriminatorio de estereotipos, sino que, además, resultaba desproporcionada en un sentido amplio.

Así, en primer lugar, el argumento referido al uso de estereotipos consistió en una secuencia de tres pasos con el fin de evaluar si la restricción al derecho a la educación de la niña Talía era discriminatoria o no. Estos pasos implicaron identificar el estereotipo en juego y luego analizar de modo estricto las razones estatales que sustentan el uso del estereotipo. Una vez identificado el trato discriminatorio, el último paso consistió en analizar si el Estado ha cumplido con el deber de adoptar medidas para erradicar estas prácticas. La Corte concluyó que no son razonables las decisiones basadas en ideas estereotipadas sobre la condición de salud de una persona y que, por tanto, los riesgos de contagios deben evaluarse en cada caso en concreto a partir de criterios objetivos y serios como, por ejemplo, informes médicos.

En segundo lugar, la Corte IDH hizo uso del examen de proporcionalidad para sostener que la expulsión de Talía representaba una medida desproporcionada en sentido amplio como consecuencia de su ausencia de idoneidad y necesidad. Creemos que la Corte tiene razón al afirmar que la medida es desproporcionada. Sin embargo, no lo es en virtud del subexamen de idoneidad. A diferencia de lo que interpretó la Corte IDH, la decisión de expulsar a Talía era técnicamente idónea (aunque en un grado ínfimamente bajo o reducido) para fomentar el fin de proteger la salud e integridad física tanto de sus compañeros como del personal de la escuela. En cualquier caso, el hecho de que la medida tuviera una eficacia «sumamente reducida» hubiera sido muy relevante en el análisis de su proporcionalidad en sentido estricto. Pero llama la atención que la Corte IDH no profundizó en forma explícita su argumentación en torno a este último punto. En cambio, la Corte IDH sí logra demostrar la desproporción por medio del subexamen de necesidad, ya que es perfectamente posible pensar en medidas informativas, preventivas o de primeros auxilios que, de haber sido adoptadas, hubieran permitido alcanzar una relación óptima o de equilibrio entre los intereses en juego, esto es, evitar la propagación del contagio del virus VIH sin afectar el derecho a la educación de Talía.

Por último, hay quienes objetan este último camino adoptado por la Corte IDH. En este sentido, se le critica que el caso debió haber sido resuelto por invocación del estándar de contenido mínimo del derecho a la educación y no evaluando la proporcionalidad de la medida. Sin embargo, esta objeción no es convincente, ya que asume supuestos de orden metodológico que resultan muy problemáticos. 


\section{Referencias}

Alexy, Robert (1986). Theorie der Grundrechte. Fráncfort del Meno: Suhrkamp.

Bernal Pulido, Carlos (2003). El principio de proporcionalidad y los derechos fundamentales. Madrid: Centro de Estudios Políticos y Constitucionales.

-. (2004). «Fundamento, concepto y estructura de los derechos sociales: Una crítica a “¿Existen derechos sociales?” de Fernando Atria». Discusiones, 4: 99-144. DOI: 10.52292/j.dsc.2004.2412.

Bilchitz, David (2008). Poverty and fundamental rights: The justification and enforcement of socio-economic rights. Oxford: Oxford University Press.

Cardoso Onofre de Alencar, Emanuela (2016). "Mujeres y estereotipos de género en la jurisprudencia de la Corte Interamericana de Derechos Humanos». Eunomía, 9: 26-48. Disponible en https://bit.ly/3isFUT9.

CLÉRICO, Laura (2009). El examen de proporcionalidad en el derecho constitucional. Buenos Aires: Eudeba.

-. (2017). «Derecho constitucional y derechos humanos: Haciendo manejable el análisis de estereotipos». Derechos en Acción, 5: 206-241. DOI: 10.24215/25251678eo94.

De Fazio, Federico (2019). Teoría principialista de los derechos sociales. Barcelona: Marcial Pons.

Lehmann, Karin (2006). «In defense of the Constitutional Court: Litigating socioeconomic rights and the myth of the minimum core». The American University International Law Review, 22 (1): 163-197. Disponible en https://bit.ly/3AXm2tO.

RonCONI, Liliana (2016). «Mucho ruido y pocos... DESC: Análisis del caso Gonzáles Lluy contra Ecuador de la Corte Interamericana de Derechos Humanos». Anuario de Derechos Humanos, 12: 119-131. DOI: 10.5354/0718-2279.2016.42745.

Timmer, Alexandra (2011). «Towards an anty-stereotyping approach for the European Court of Human Rights». Human Rights Law Review, 11 (4): 707-738. DOI: 10.1093/hrlr/ngro36.

Young, Katherine (2012). Constituting economic and social rights. Oxford: Oxford University Press.

\section{Sobre los autores}

Celeste Novelli es docente de la Universidad de Buenos Aires, Argentina, y magíster en Derechos Humanos y Democratización en Latinoamérica del Centro Internacional de Estudios Políticos de la Universidad Nacional de San Martín, Argentina. Doctoranda en Derecho Constitucional de la Universidad de Buenos Aires y exbecaria del Conicet, Argentina. Actualmente se desempeña como abogada en la Corte Interamericana de Derechos Humanos (las opiniones aquí vertidas son de su exclusiva responsabilidad y no reflejan necesariamente el parecer de la Corte Interamericana 
ni de su Secretaría). Su correo electrónico es celestenovelli@gmail.com. (D) https:// orcid.org/0000-0001-7261-1669.

Federico de FAzio es abogado, magíster y doctor por la Universidad de Buenos Aires. Investigador asistente del Conicet. Docente de la Universidad de Buenos Aires.Su correo electrónico es federicodefazio@derecho.uba.ar. (D) https://orcid. org/0000-0002-8562-6939. 
El Anuario de Derechos Humanos es una publicación semestral de referencia y consulta en materia de derechos humanos y campos afines. Busca ser un espacio de discusión de los temas centrales en el ámbito nacional e internacional sobre derechos humanos. Es publicado desde 2005 por el Centro de Derechos Humanos de la Facultad de Derecho de la Universidad de Chile.

\author{
EDITORA \\ Claudia Iriarte Rivas \\ ciriarter@derecho.uchile.cl \\ SITIO WEB \\ anuariocdh.uchile.cl \\ CORREO ELECTRÓNICO \\ anuario-cdh@derecho.uchile.cl \\ LICENCIA DE ESTE ARTÍCULO \\ Creative Commons Atribución Compartir Igual 4.o Internacional
}

\author{
\% \\ La edición de textos, el diseño editorial \\ y la conversión a formatos electrónicos de este artículo \\ estuvieron a cargo de Tipográfica \\ (www.tipografica.io)
}

